\title{
Fatigue Intensity in Cervical and Breast Cancer Survivors: Difference in Each Stage of Cancer Survivorship
}

\author{
Ni Putu Wulan Purnama Sari \\ Department of Palliative Nursing, Faculty of Nursing, Widya Mandala Catholic University Surabaya, Indonesia
}

\section{ARTICLE INFO}

Received : 10 January 2019

Reviewed: 11 February 2019

Accepted : 12 March 2019

\section{Keywords:}

breast cancer, cancer-related

fatigue, cancer survivor, cervical

cancer, fatigue

\begin{abstract}
Background: Cervical and breast cancers are the two top leading cases of female cancer in Indonesia. Nowadays, many survivors with various degree of cancer-related fatigue (CRF) were found in the community context. This study aimed to compare and analyse the differences of CRF intensity in cervical cancer survivors (CCS) and breast cancer survivors (BCS) generally, and in each stage of cancer survivorship, specifically.
\end{abstract}

Methods: This cross-sectional study involved 47 CCS and 55 BCS in the district of Rangkah, Gading, and Pacar Keling, Surabaya, Indonesia ( $n=102)$. Instrument of Fatigue Symptom Inventory (FSI) was used for data collection. Descriptive statistic, independent sample t-test, and one way ANOVA test were used for data analysis $(\alpha<.05)$.

Results: Most respondents were short term survivors (43.14\%) with mild CRF (66.67\%) in both cases. Higher intensity of CRF was found in CCS compared to BCS. Worst CRF was found more in acute and short term survivorship in BCS compared to more in long term survivorship in CCS. There was no significant difference of CRF found between CCS and BCS ( $p=.63)$, and CRF was not significantly different between each stage of cancer survivorship in both cases ( $p=.883$ and $p=.117$ for CCS and BCS respectively), but CRF intensity in the worst and lightest time possible was significantly different between CCS and $B C S(p=.000)$.

Conclusions: There was no significant difference of CRF between cases and stages of survivorship in CCS and BCS, but CRF intensity in the worst and lightest time possible was significantly different between those groups.

\section{INTRODUCTION}

Cancer is defined as a disease in which certain genes that control the process of cell regeneration in the human body become damaged and led the cells to grow abnormally (1). A study in 187 countries from 1980 until 2010 was conducted to analyze the epidemiology of cervical and breast cancer incidence and mortality worldwide. Global breast cancer incidence increased from 641,000 (95\% uncertainty intervals 610,000$750,000)$ cases in 1980 to $1,643,000 \quad(1,421,000-$ $1,782,000$ ) cases in 2010 , with an increasing annual rate of $3.1 \%$. Global cervical cancer incidence increased from $378,000(256,000-489,000)$ cases per year in 1980 to $454,000(318,000-620,000)$ cases per year in 2010indicating $0.6 \%$ annual rate of increase. Breast cancer killed $425,000(359,000-453,000)$ women in 2010 , of whom $68,000(62,000-74,000)$ were aged $15-49$ years in developing countries. Cervical cancer death rates have been decreasing but the disease still killed 200,000
$(139,000-276,000)$ women in 2010 , of whom 46,000 $(33,000-64,000)$ were aged $15-49$ years in developing countries (2).

Nationally, it can be estimated that the incidence of cancer in Indonesia is $0.1 \%$ of the population, and more than $50 \%$ of cancer patients first come to seek for medication in advance stages (3). In 2013, the prevalence of cancer in Indonesia was $1.4 \%$ in which the prevalence of breast and cervical cancer was $0.8 \%$ and $0.5 \%$, respectively with the state of Yogyakarta holding the 1st position for the highest cancer prevalence (4). In 2014, breast cancer occupied the 1st position of the leading cause of death, followed by cervical cancer in the 2nd place (5). In 2017, breast cancer still held the 1 st position as the highest new cases and deaths in Indonesian cancer statistics (6). In the period of four years, we can see that more women suffered from cancer. Cervical and breast cancers have been the top two leading cases of female cancer in Indonesia for several years until now. These phenomena of female 
cancers possibly happen because more women reported higher psychological stress level than men (7), and women frequently use hormonal contraceptives (8), such as pills/injection/implant; both are inducing cancer, especially breast cancer $(8,9)$.

Breast and cervical cancers have emerged as major global health challenges and disproportionately lead to excess morbidity and mortality in low- and middleincome countries when compared to high-income countries (10). Every year, more than 2 million women worldwide are diagnosed with breast or cervical cancer, yet where a woman lives, her socioeconomic status and agency largely determines whether she will develop one of these cancers and will ultimately survive (11). The life expectancy of people living with cancer increases steadily, making cancer one of the non-communicable diseases (NCD) with long term burden that needs longterm supportive and palliative care. The stage of survivorship in cancer categorizes into three, namely: acute $(<1$ year), short term (1-5 years), and long term survivorship ( $>5$ years) (12). The hybrid model suggests that cancer-related stressors and cancer therapies cause a decrease in four major areas that are cognitive function, nutrition, muscle strength, and sleep quality, affecting the ability to adapt to ill conditions (13). The prolonged total pain and/or suffering, especially in longterm cancer survivors, will further adversely affect the health-related quality of life (QOL).

In general, cancer therapy includes surgery, chemotherapy, and radiotherapy. A symptom that is often experienced by the majority of cancer patients, especially those who are undergoing chemotherapy or radiation therapy, is cancer-related fatigue (CRF) (14). In people living with cancer, changes in the biological, psychological, and functional aspects also result in CRF (13). The National Comprehensive Cancer Network (2015) defines CRF as a distressing, persistent, subjective sense of physical, emotional, and/or cognitive tiredness or exhaustion related to cancer or cancer treatment that is not proportional to recent activity and interferes with usual functioning (15). The negative impact of CRF can even be felt before the formal diagnosis of cancer established, and continues to be experienced during the treatment process. CRF has a significant impact on health status (16). CRF is subjective, which can affect physical and cognitive function, psychosocial, and can reduce QOL (17). A prior study by Sari (2018) towards 129 cancer survivors (58 breast cancer, 47 cervical cancer, and 24 other cancer survivors) found that CRF influenced QOL significantly by $53.60 \%(p=.000)(18)$.

This study aims to compare and analyze the differences of CRF intensity in cervical cancer survivors (CCS) and breast cancer survivors (BCS) generally, and in each stage of cancer survivorship, specifically. Cervical cancer and breast cancer have different etiology, symptoms, and complications. The longer the women live with cervical or breast cancer, the more cancerrelated stressor, and treatments exposed towards them. Therefore there is a high possibility that CRF intensity will be different not only between cervical and breast cancer but also between each stage of cancer survivorship within. By knowing the results of this study, it will be beneficial for developing a particular intervention by targeting CRF factors' modification (possible etiology) and finding suitable management in every stage of cancer survivorship in CCS and BCS.

\section{METHODS}

This cross-sectional study involved 47 CCS and 55 BCS in the district of Rangkah, Gading, and Pacarkeling, Surabaya, Indonesia. Cancer survivorship was divided into 3 categories: 1 ) acute (< 1 year), 2) short term (1-5 years), and 3) long term survivorship ( $>5$ years) [9]. Inclusion criteria consisted of: 1 ) being an adult (> 18 years old); 2) cancer diagnosis has been confirmed; 3 ) regularly home-visited by a palliative volunteer under the supervision of Rangkah Public Health Center, Surabaya, and; 4) CRF was being one of the cancer symptom experienced in the period of one week prior to the data collection process. Exclusion criteria were rejection on filling out the consent form, very poor condition, and consciousness loss or disorientation. Total sampling was applied and the sample size of 102 subjects was obtained. Instrument of Fatigue Symptom Inventory (FSI), which was developed by Moffitt Cancer Center and University of South Florida (1998), was used for data collection (19). Fatigue Symptom Inventory (FSI) has 14 items. The score range for each item is $0-10$. It means total score is between 0-140. CRF was divided into 3 categories based on FSI total score: 1) mild fatigue (total score 1-47); 2) moderate fatigue (total score 48-93); and 3) severe fatigue (total score 94-140). These 3 categories were made just to ease the data presentation in the result section, but for statistical analysis I used the pure total score to be analyzed further.

Data were collected from February until March 2018. Descriptive statistic, independent sample t-test, and one-way analysis of variance (ANOVA) test were used for data analysis $(\alpha<.05)$. Ethical clearance was issued by the Faculty of Nursing, Universitas Airlangga, Surabaya, Indonesia, with certificate number of 681KEPK.

\section{RESULTS}

Most respondents were Javanese, Islam, married, housewife, with monthly income (GDP) less than the minimum wage of Surabaya in 2018 (IDR 3,300,000.00). 
Table 1. Demographic characteristics

\begin{tabular}{|c|c|c|}
\hline \multirow[t]{2}{*}{ Characteristics } & $\begin{array}{l}\text { Cervical Cancer } \\
(n=47)\end{array}$ & $\begin{array}{l}\text { Breast Cancer } \\
(n=55)\end{array}$ \\
\hline & Frequency (\%) & Frequency (\%) \\
\hline \multicolumn{3}{|l|}{ Age (years old) } \\
\hline$<21$ & $0(0)$ & $0(0)$ \\
\hline $21-30$ & $0(0)$ & $5(9.09)$ \\
\hline $31-40$ & $5(10.64)$ & $10(18.18)$ \\
\hline $41-50$ & $11(23.40)$ & $13(23.64)$ \\
\hline $51-60$ & $17(36.17)$ & $15(27.27)$ \\
\hline $61-70$ & $13(27.66)$ & $8(14.54)$ \\
\hline$>70$ & $1(2.13)$ & $4(7.27)$ \\
\hline \multicolumn{3}{|l|}{ Religion } \\
\hline Catholic & $0(0)$ & $1(1.82)$ \\
\hline Christian & $7(14.89)$ & $10(18.18)$ \\
\hline Islam & $40(85.11)$ & $44(80.0)$ \\
\hline \multicolumn{3}{|l|}{ Ethnic } \\
\hline Javanese & $40(85.11)$ & $54(98.18)$ \\
\hline Maduranese & $6(12.76)$ & $0(0)$ \\
\hline Chinese & $1(2.13)$ & $1(1.82)$ \\
\hline \multicolumn{3}{|l|}{ Educational background } \\
\hline Primary school & $15(31.91)$ & $11(20.0)$ \\
\hline Secondary school & $14(29.79)$ & $5(9.09)$ \\
\hline High school & $13(27.66)$ & $24(43.64)$ \\
\hline Diploma/Bachelor degree & $2(4.25)$ & $14(25.45)$ \\
\hline Uneducated & $3(6.38)$ & $1(1.82)$ \\
\hline \multicolumn{3}{|l|}{ Marital status } \\
\hline Single & $3(6.38)$ & $6(10.91)$ \\
\hline Married & $39(82.98)$ & $35(63.64)$ \\
\hline Widow & $4(8.51)$ & $14(25.45)$ \\
\hline Divorce & $1(2.13)$ & $0(0)$ \\
\hline \multicolumn{3}{|l|}{ Living at home with ${ }^{\mathrm{a}}$} \\
\hline Spouse & 39 (82.98) & $29(52.73)$ \\
\hline Children & $17(36.17)$ & $34(61.82)$ \\
\hline Alone & $3(6.38)$ & $2(3.64)$ \\
\hline Parents & $0(0)$ & $9(16.36)$ \\
\hline Sibling & $0(0)$ & $2(3.64)$ \\
\hline \multicolumn{3}{|l|}{ Occupational status } \\
\hline Full-timer & $2(4.25)$ & $9(16.36)$ \\
\hline Part-timer & $3(6.38)$ & $2(3.64)$ \\
\hline Retired & $0(0)$ & $4(7.27)$ \\
\hline Housewife & $40(85.11)$ & $36(65.45)$ \\
\hline Seeking job & $0(0)$ & $1(1.82)$ \\
\hline Unemployed & $2(4.25)$ & $3(5.45)$ \\
\hline \multicolumn{3}{|l|}{ Monthly income } \\
\hline$<$ minimum wage & $34(72.34)$ & $32(58.18)$ \\
\hline Minimum wage & $8(17.02)$ & $13(23.64)$ \\
\hline > Minimum wage & $3(6.38)$ & $6(10.91)$ \\
\hline No income & $2(4.25)$ & $3(5.45)$ \\
\hline
\end{tabular}

${ }^{a}$ Respondents may choose more than 1 answer

${ }^{\mathrm{b}}$ IDR 5 million

Educational background, occupational status, and monthly income were better in the group of BCS. The majority was aged 51-60 years old in both cases, but CCSs tend to be older than BCSs. Cervical cancer survivors (CSS) who were married mostly had no child, but most BCS live with their spouse and children. More single women were found to have breast cancer in this study. Table 1 shows the demography characteristic of study respondents in details.
The majority of respondents in both groups were diagnosed before 2014 (more than five years ago). Most breast cancer survivors undertook surgery only, for both curative and palliative purposes. In the other hand, most cervical cancer survivors undertook a more complex regiment, which is a combination of surgery and chemo-radiotherapy. Table $\mathbf{2}$ shows the time of first diagnosis and the therapeutic regiments for both cases in details.

Most respondents were short term survivors (43.14\% in total) with mild CRF (66.67\% in total). More acute survivors were found in breast cancer cases (32.73\%). Mild CRF was found in the majority for all stages of cancer survivorship in both cases, but more severe CRF was found in short term survivors in the case of cervical cancer (8.7\%) compared to other stages and cases. As for moderate CRF, it was found more in short and long term survivors in the case of cervical cancer, compared to more in acute and short term survivors in the case of breast cancer. Table $\mathbf{3}$ shows the CRF level in all stages of cancer survivorship for both cases in details.

Descriptive statistic results showed that CRF mean and standard deviation (SD) in the CCS group were 39.98 and 24.78 respectively, while for BCS group the CRF mean and SD were 37.44 and 27.75 respectively. This indicates that more severe CRF was found in CCSs and data was more homogenous compared to BCS because of lower SD.

Table 2. Primary data

\begin{tabular}{|c|c|c|}
\hline \multirow[t]{2}{*}{ Characteristics } & $\begin{array}{l}\text { Cervical } \\
\text { Cancer }(n=47)\end{array}$ & $\begin{array}{l}\text { Breast Cancer } \\
(n=55)\end{array}$ \\
\hline & Frequency (\%) & Frequency (\%) \\
\hline \multicolumn{3}{|l|}{ Firstly diagnosed } \\
\hline 2018 & $0(0)$ & $4(7.72)$ \\
\hline 2017 & $7(14.89)$ & $14(25.45)$ \\
\hline 2016 & $12(25.53)$ & $7(12.73)$ \\
\hline 2015 & $5(8.62)$ & $10(18.18)$ \\
\hline 2014 & $5(8.62)$ & $2(3.64)$ \\
\hline$<2014$ & $18(38.30)$ & $18(32.73)$ \\
\hline \multicolumn{3}{|l|}{ Type of therapy } \\
\hline Surgery & $5(8.62)$ & $24(43.64)$ \\
\hline Chemotherapy & $13(27.66)$ & $8(14.55)$ \\
\hline Surgery + chemotherapy & $2(4.25)$ & $10(18.18)$ \\
\hline Surgery + radiotherapy & $0(0)$ & $1(1.82)$ \\
\hline $\begin{array}{l}\text { Chemotherapy + } \\
\text { radiotherapy }\end{array}$ & 7 (14.89) & $1(1.82)$ \\
\hline $\begin{array}{l}\text { Surgery }+ \text { chemotherapy }+ \\
\text { radiotherapy }\end{array}$ & $17(36.17)$ & $5(9.09)$ \\
\hline $\begin{array}{c}\text { Surgery + chemotherapy + } \\
\text { radiotherapy + analgesic }\end{array}$ & $1(2.13)$ & $0(0)$ \\
\hline $\begin{array}{l}\text { Surgery + chemotherapy }+ \\
\text { radiotherapy + medicine }\end{array}$ & $1(2.13)$ & $0(0)$ \\
\hline $\begin{array}{l}\text { Surgery }+ \text { chemotherapy }+ \\
\text { oral medicine }\end{array}$ & $0(0)$ & $1(1.82)$ \\
\hline Oral medicine (various) & $0(0)$ & $4(7.27)$ \\
\hline Untreated & $1(2.13)$ & $1(1.82)$ \\
\hline
\end{tabular}


Table 3. Comparison of CRF in all stages of survivorship between CCS and BCS

\begin{tabular}{|c|c|c|c|}
\hline Case & $\begin{array}{l}\text { Survivorship } \\
\text { Stage }\end{array}$ & CRF Level* & $\begin{array}{l}\text { Frequency } \\
\text { (\%) }\end{array}$ \\
\hline \multirow{9}{*}{$\begin{array}{c}\text { Cervical } \\
\text { cancer } \\
(n=47)\end{array}$} & \multirow{3}{*}{$\begin{array}{l}\text { Acute } \\
(n=7)\end{array}$} & Mild & $6(12.77)$ \\
\hline & & Moderate & $1(2.13)$ \\
\hline & & Severe & $0(0)$ \\
\hline & \multirow{3}{*}{$\begin{array}{l}\text { Short term } \\
(n=23)\end{array}$} & Mild & $17(36.17)$ \\
\hline & & Moderate & $4(8.51)$ \\
\hline & & Severe & $2(4.26)$ \\
\hline & \multirow{3}{*}{$\begin{array}{l}\text { Long term } \\
(n=17)\end{array}$} & Mild & $12(25.53)$ \\
\hline & & Moderate & $5(10.64)$ \\
\hline & & Severe & $0(0)$ \\
\hline \multirow{9}{*}{$\begin{array}{l}\text { Breast } \\
\text { cancer } \\
(n=55)\end{array}$} & \multirow{3}{*}{$\begin{array}{l}\text { Acute } \\
(n=18)\end{array}$} & Mild & $10(18.18)$ \\
\hline & & Moderate & 7 (12.73) \\
\hline & & Severe & $1(1.82)$ \\
\hline & \multirow{3}{*}{$\begin{array}{l}\text { Short term } \\
(n=21)\end{array}$} & Mild & $11(20.0)$ \\
\hline & & Moderate & $9(16.36)$ \\
\hline & & Severe & $1(1.82)$ \\
\hline & \multirow{3}{*}{$\begin{array}{l}\text { Long term } \\
(n=16)\end{array}$} & Mild & $12(21.82)$ \\
\hline & & Moderate & $3(5.45)$ \\
\hline & & Severe & $1(1.82)$ \\
\hline
\end{tabular}

*Category was made to ease the data presentation, and not for statistical analysis purposes

Independent sample t-test showed that there was no significant difference of CRF between CCS and BCS ( $p$ $=.63$ ), but deeper analysis towards each item of FSI showed a significant difference in CRF intensity, especially in item 1 and 2 about the worst and lightest time possible of daily CRF (@ $p=.000$ ). Most BCS reported milder CRF even in the worst time possible compared to CCS, while most CCS reported moderate CRF even in the lightest time possible compared to BCS. More severe CRF intensity was found more in CCS than BCS; this confirmed the results of descriptive statistic above. Table 4 and 5 shows the CRF intensity between CCS and BCS in details.

One way ANOVA test results showed that CRF was not significantly different between each stage of cancer survivorship in both cases $(p=.883$ and $p=.117$ for CCS and BCS respectively), and deeper analysis also showed that there was no significant difference in each item of FSI in both cases ( $p>\alpha$ for all items of FSI). Table 6 and 7 shows the result of one way ANOVA in details.

Table 4. Comparison of CRF intensity between BCS and CCS

\begin{tabular}{|c|c|c|c|c|c|c|}
\hline Cases & mean & SD & Cl95\% & $t$ & $F$ & $p$-value \\
\hline $\begin{array}{l}\text { Breast } \\
\text { cancer } \\
(n=55)\end{array}$ & 37.44 & 27.74 & \multirow{2}{*}{$\begin{array}{c}-7.87 \\
- \\
12.96\end{array}$} & .489 & \multirow{2}{*}{2.471} & \multirow{2}{*}{$p=.63$} \\
\hline $\begin{array}{l}\text { Cervical } \\
\text { cancer } \\
(n=47)\end{array}$ & 39.98 & 24.78 & & .484 & & \\
\hline
\end{tabular}

Table 5. Comparison of CRF intensity in the worst and lightest time of daily CRF between CCS and BCS

\begin{tabular}{|c|c|c|c|}
\hline Item of FSI & Case & $\begin{array}{l}\text { CRF } \\
\text { Intensity* }\end{array}$ & $\begin{array}{l}\text { Frequency } \\
\text { (\%) }\end{array}$ \\
\hline \multirow{6}{*}{$\begin{array}{l}\text { Q1: Rate your level } \\
\text { of fatigue on the } \\
\text { day you felt most } \\
\text { fatigued during the } \\
\text { past week! }\end{array}$} & \multirow{3}{*}{$\begin{array}{l}\text { Cervical } \\
\text { cancer }\end{array}$} & Mild & $8(17.02)$ \\
\hline & & Moderate & $18(38.30)$ \\
\hline & & Severe & 21 (44.68) \\
\hline & \multirow{3}{*}{$\begin{array}{l}\text { Breast } \\
\text { cancer }\end{array}$} & Mild & $26(47.27)$ \\
\hline & & Moderate & 21 (38.18) \\
\hline & & Severe & $8(14.55)$ \\
\hline \multirow{6}{*}{$\begin{array}{l}\text { Q2: Rate your level } \\
\text { of fatigue on the } \\
\text { day you felt least } \\
\text { fatigued during the } \\
\text { past week! }\end{array}$} & \multirow{3}{*}{$\begin{array}{l}\text { Cervical } \\
\text { cancer }\end{array}$} & Mild & $20(42.55)$ \\
\hline & & Moderate & 23 (48.94) \\
\hline & & Severe & $4(8.51)$ \\
\hline & \multirow{3}{*}{$\begin{array}{l}\text { Breast } \\
\text { cancer }\end{array}$} & Mild & $42(76.36)$ \\
\hline & & Moderate & 10 (18.18) \\
\hline & & Severe & $3(5.45)$ \\
\hline
\end{tabular}

*Category was made to ease the data presentation, and not for statistical analysis purposes

Table 6. Comparison of CRF intensity between each stage of cancer survivorship in BCS based on FSI scores

\begin{tabular}{llllll}
\hline $\begin{array}{l}\text { Survivor } \\
\text { Stages }\end{array}$ & mean & SD & Cl95\% & F & p-value \\
\cline { 1 - 3 } $\begin{array}{l}\text { Acute } \\
(n=18)\end{array}$ & 37.44 & 27.74 & & & \\
\cline { 1 - 3 } $\begin{array}{l}\text { Short-term } \\
(n=21)\end{array}$ & 39.98 & 24.78 & $\begin{array}{c}-11.09 \\
-\end{array}$ & 2.234 & $p=.117$ \\
\cline { 1 - 2 } $\begin{array}{l}\text { Long-term } \\
(n=16)\end{array}$ & 25.38 & 17.47 & & & \\
\hline
\end{tabular}

Table 7. Comparison of CRF intensity between each stage of cancer survivorship in CCS based on FSI scores

\begin{tabular}{llllll}
\hline $\begin{array}{l}\text { Survivor } \\
\text { Stages }\end{array}$ & mean & SD & Cl95\% & F & p-value \\
\cline { 1 - 3 } Acute $(n=7)$ & 35.57 & 14.52 & & & \\
\cline { 1 - 3 } $\begin{array}{l}\text { Short-term } \\
(n=23)\end{array}$ & 40.78 & 25.91 & $\begin{array}{c}-21.74 \\
-\end{array}$ & .125 & $p=.883$ \\
\cline { 1 - 3 } $\begin{array}{l}\text { Long-term } \\
(n=17)\end{array}$ & 40.71 & 27.44 & & & \\
\hline
\end{tabular}

\section{DISCUSSION}

Cancer is a large group of diseases characterized by uncontrolled growth of abnormal cells that are able to invade other tissues and spread to other parts of the body. Surviving cancer often requires treatment with multimodal therapy that can last many months or years: surgery, radiation therapy, chemotherapy, hormone or endocrine therapy, biologic or immunotherapy, targeted therapies, and stem cell transplantation (20). Results showed that most respondents were short term survivors (43.14\% in total). Proportion of survivorship in CCS ( $n=47)$ compared to BCS $(n=55)$ for acute : shortterm : long-term survivorship was $7: 23: 17$ compared to $18: 21: 16$ respectively. This indicates that the 
survival rate of breast and cervical cancer is particularly long, which makes both types of cancer a chronic disease with high burden that requires long-term and supportive/palliative care. More acute survivors were found in the case of breast cancer $(32.73 \%)$, but this possibly happens because more BCS participated in this study compared to CCS. This result indicates that the stage of survivorship found in the community setting of Surabaya between CCS and BCS was similar. There was no significant disparity found between CCS and BCS regarding survivorship. Nowadays, advances have occurred in the area of female cancer survivorship, but sometimes challenges and gaps in relevant information remain.

A study towards 379 BCS about their perspectives regarding their experiences of the survivorship continuum from diagnosis through 30 months posttreatment showed that social support and positive worldviews were the themes with the most significant impact on long-term breast cancer survivorship experiences. Breast Cancer Survivors (BCS) expressed a need to advance their health care literacy in order to share ownership of breast cancer and lymphedema treatment decisions. Since breast cancer is an immunemediated disease, long-term survivorship planning should address psychosocial factors that influence the long-term psychological distress associated with immune dysfunction (21). Obesity has been associated with breast cancer recurrence and poorer survival (22). A similar study in the case of cervical cancer is not found yet.

CRF is a distressing, persistent, subjective sense of physical, emotional, and/or cognitive tiredness or exhaustion related to cancer or cancer treatment that is not proportional to recent activity and interferes with usual functioning (15). Cancer-related fatigue (CRF) is a highly prevalent symptom experienced by most cancer patients during, and often for considerable periods after, treatment (17). There are three categories of CRF as proposed by the Canadian Association of Psychosocial Oncology, namely: mild, moderate, and severe CRF, with different indicators and management (23). Mild CRF is characterized by minimal fatigue symptoms, and able to carry out activities of daily living [self-care, homemaking, work, leisure]. Moderate CRF is characterized by symptoms that cause moderate to high levels of distress, a decreasing activity of daily living (ADLs), and some impairment in physical functioning. Severe CRF is characterized by significant fatigue on a daily basis, excessive need to sit or sleep, severe impairment of activity of daily living, sudden onset of fatigue and/or shortness of breath at rest, rapid heart rate and/or blood loss.

Screening for CRF is needed at the entry to health care system, periodically throughout treatment, posttreatment follow-up and advanced disease. CRF guidelines were proposed by Howell, et al. (2015) and were recommended by the Canadian Association of Psychosocial Oncology (23). Cancer-related fatigue (CRF) prevention and supportive care interventions for all cancer patients and caregivers include: 1) education about the difference between normal and CRF, treatment-related fatigue patterns/fluctuations, persistence of CRF post-treatment, causes (contributing factors) of CRF, consequences of CRF, benefits of physical activity during and post-treatment, and signs and symptoms of worsening CRF to report to health care professionals; 2 ) counseling about how to balance energy conservation with activity, and use of distraction such as games, music, reading, and socializing; 3) encouragement for patients to use a treatment log or diary to monitor levels and patterns of CRF, to help ascertain peak energy periods, and to help with planning activities.

Results showed that most respondents experienced mild CRF (66.67\% in total). Mild CRF was found in the majority of all stages of cancer survivorship in both cases. Generally, higher CRF intensity was found in CCS compared to BCS with mean of 39.98 compared to 37.44 respectively. Higher intensity of CRF was found in CCS, but there was no significant difference in CRF found between CCS and BCS ( $p=.63)$. One way ANOVA test results showed that CRF was not significantly different between each stage of cancer survivorship in both cases $(p=.883$ and $p=.117$ for CCS and BCS respectively).

There was $60 \%$ of BCS with mild CRF found in this study. Mild CRF was found in the majority in all survivorship stages in BCS. In the case of breast cancer, the experience of CRF is one of the most common and debilitating symptoms of breast cancer treatment. A qualitative study towards 10 BCS showed that every woman had a very individualized CRF experience, yet, there were also some perspective similarities. Living with CRF resulted in fear and uncertainty in BCS; however, with the passage of time, most BCS discovered positive aspects of their experience (24). A similar study in the case of cervical cancer was not found. There were $74.47 \%$ CCS with mild CRF found in this study. Mild CRF was found in the majority in all survivorship stage in CCS. Although fewer CCS participated in this study, we found more patients with mild CRF in CCS compared to BCS which was only $60 \%$.

Moderate CRF was found more in long term survivors in the case of cervical cancer compared to more in acute and short term survivors in the case of breast cancer. In the case of cervical cancer, a higher intensity of CRF was found in the later stage of survivorship. This possibly happens due to therapy complexity and malnutrition. Results showed that most CCS undertook a more complex regiment compared to $\mathrm{BCS}$, which is a combination of surgery and chemoradiotherapy (36.17\%). Post-chemotherapy, cancer patients may experience malnutrition; even before 
treatment they often have metabolic disorders (25). Malnutrition and weight loss in cancer patients are caused by several mechanisms of cancer and host response to tumors and anti-cancer therapy. In addition, lack of energy, protein and/or other nutrients in malnourished patients can cause opposite effects on body tissue formation, body composition, body function, and clinical outcome, especially CRF. Malnutrition is associated with decreased survival rate, therapeutic response, and QOL in cancer patients (16).

Severe CRF was found more in short term survivors of CCS (8.7\%) compared to other stages and BCS. There are some factors related to the severity of CRF in cancer patients. Female gender, being unemployed, higher cancer stage (III-IV) at diagnosis, receiving active treatment at the time of study participation, being treated with palliative intent, having had radiotherapy, higher fear of recurrence or progression, and higher psychological distress was significantly correlated with CRF severity (26). A study towards 139 women living with breast cancer in communities of Surabaya showed that those with breast cancer mostly aged middle-up adulthood compared to older age in cervical cancer, and the number of early adults and adolescent female with breast or cervical cancer cannot be ignored $17.17 \%$ in total) (27). Therefore, detection and management of severe CRF in cancer patients, especially in late adolescence or young adulthood, is really important because it could affect QOL significantly (26).

A previous study towards African-American women with breast cancer showed that common side effects, including CRF, loss of strength, difficulty sleeping, and sexual dysfunction, last for long periods after cancer treatment (22). This study found that in the case of breast cancer, higher intensity of CRF was found more in earlier survivorship stage compared to CCS. A significant difference was found in CRF intensity item 1 and 2 in the worst and lightest time possible (@ $p=.000$ ). Most BCS reported milder CRF even in the worst time possible compared to CCS, while most CCS reported moderate CRF even in the lightest time possible compared to BCS. Therefore, these study results challenge the findings of this previous study, especially in the field of CRF if compared to CCS. In BCS, higher intensity of CRF which was found more in earlier survivorship stage possibly due to impaired psychological wellbeing. Cancer-Related Fatigue (CRF) is a subjective experience which can be influenced by psychological state (17). Prior study results found more severe clinical manifestations of cancer in CCS compared to BCS, including CRF, but surprisingly CCS expressed better health status than BCS (28). This finding indicates that CCS implemented a more adaptive coping strategy in facing the disease, especially in the earlier stage of survivorship. Even so, physical wellbeing was found better in BCS. This may be influenced by various factors involving disease mechanism, host response towards tumor/cancer, and the side effect of anti-cancer therapy (28).

Prior study results showed that there was no significant difference in therapy between cases $(p=$ .076); although chemotherapy has no significant effect on CRF in both cases ( $p=.060$ and $p=.784$ for CCS and $\mathrm{BCS}$ respectively) but there was a significant difference of CRF found between CCS and BCS who received chemotherapy as one of their cancer regiments ( $p=$ .009) (29). This study results showed that CRF did not differ significantly between cases and between stages of survivorship. However, the intensity of CRF was determined by cases in this study context. Therefore, the type of cancer and chemotherapy are the two factors that determine CRF intensity in the case of female cancer.

\section{CONCLUSION}

There was no significant difference of CRF between CCS and BCS, but a significant difference of CRF intensity was found in the worst and lightest time possible between cases. There was no significant difference of CRF found between stages of cancer survivorship in both cases. Higher intensity of CRF was found in CCS compared to BCS. Worst CRF was found more in acute and short term survivorship in BCS compared to more in long term survivorship in CCS. CRF intensity is determined by cases in women living with cancer.

\section{DECLARATIONS}

\section{Ethical approval}

This study protocol has been reviewed for ethical purposes. Ethical clearance was issued by the Faculty of Nursing, Universitas Airlangga, Surabaya, Indonesia, with certificate number of 681-KEPK. Prior to data collection, all respondents got an explanation about study benefits and potential risk and other technical instructions. All respondents had signed the consent forms and expressed the agreement to participate in this study.

\section{Competing of Interest}

I declare that I do not have any competing interest, especially with the study funder.

\section{Acknowledgement}

This study was funded by the Center of Food and Nutritional Research, Institute of Research and Community Service, Widya Mandala Catholic University Surabaya, by Grant number: 077a/WM01.5.2/N/2018. This publication was supported by the Faculty of Nursing, Widya Mandala Catholic University Surabaya. 


\section{REFERENCES}

1. Kaplan M. The Hispanic outlook in higher education. Paramus. 2008; 18(17): 42-44.

2. Forounzafar $\mathrm{MH}$, Foreman $\mathrm{KJ}$, Delossantos $\mathrm{AM}$, Lozano R, Lopez AD, Murray CJL, Naghavi M. Breast and cervical cancer in 187 countries between 1980 and 2010: a systematic analysis,. The Lancet. 2011; 378(9801): 1461-1484.

3. Tejawinata S. Surabaya, The City of Palliative: Its Image and Charm (in Bahasa Indonesia). 2012. Surabaya: Airlangga University Press.

4. Irawan KI. Cancer detection (in Bahasa Indonesia). Kompas. Retrieved from: https://www.pressreader.com/indonesia/kompas/2 $0180312 / 282475709343993$

5. World Health Organization (WHO). Cancer Country Profiles (2014). 2015. Retrieved from: https://www.who.int/cancer/country-profiles/en/

6. Arafah ABR, Notobroto HB. Factors associated with housewives behavior in doing breast selfassessment (in Bahasa Indonesia). The Indonesian Journal of Public Health. 2017; 12(2): 143-153.

7. American Psychological Association. Gender and stress. 2010. Retrieved from: https://www.apa.org/news/press/releases/stress/2 010/gender-stress.aspx

8. Westhoff $\mathrm{CL}$, Pike MC. Hormonal contraception and breast cancer. Am J Obstet Gynecol. 2018; 219(2): 169.e1-169.e4.

9. Chiriac V-F, Baban A, Dumitrascu DL. Psychological stress and breast cancer incidence: a systematic review. 2018; 91(1): 18-26.

10. Demment MM, Peters $K$, Dykens JA, Dozier $A$, Nawaz $H$, Mclntosh S, Smith JS, Sy A, Irwin T, Fogg TT, Khaliq M, Blumenfeld R, Massoudi M, De Ver Dye T. Developing the evidence base to inform best practice: a scoping study of breast and cervical cancer reviews in low- and middle-income countries. PLoS ONE. 2015; 10(9): e0134618.

11. Ginsburg O, Bray, F, Coleman MP, Vanderpuve V, Eniu A, Kotha SR, Sarker M, Huong TT, Allemani, C, Dvaladze A, Gralow J, Yeates K, Taylor C, Oomman N, Khrishnan S, Sullivan R, Kombe D, Blas MM, Parham G, Kassami N, Conteh L. The global burden of women's cancers: a grand challenge in global health. The Lancet Series: Health, Equity, and Women's Cancers 2. 2017; 389: 847-860.

12. Campo RA, Lenjek KL, Gaylord-scott N, Faurot KR, Smith S, Asher G, Porterfield D, Gaylord SA. Weathering the seasons of cancer survivorship: mind-body therapy use and reported reasons and outcomes by stages of cancer survivorship. Supportive Care in Cancer Survivorship. 2016; 24(9): 3783-3791.
13. Mitchell S. Cancer-related fatigue: state of the science. Am Acad Phys Med Rehabil R. 2010; 5: 609617.

14. Borneman T. Assessment and management of cancer-related fatigue. Journal of Hospice \& Palliative Nursing. 2013; 15(2): 77-86.

15. The National Comprehensive Cancer Network. Cancer-related fatigue-version 2.2015. Natl Compr Canc Netw. 2015; 13: 1012-1039.

16. Andreoli A, de Lorenzo A, Cadeddu F, Grande M. New trends in nutritional status assessment of cancer patients. European Review for Medical and Pharmacological Sciences. 2011; 15: 469-480.

17. Jean-Pierre $P$, Figueora-Moseley $C D$, Kohli $S$, Fiscella K, Palesh OG, Morrow GR. Assessment of cancerrelated fatigue: implications for clinical diagnosis and treatment. The Oncologist. 2007; 12(12): 11-21.

18. Sari NPWP. The influence of nutritional status and cancer-related fatigue (CRF) on quality of life in cancer survivors. Proceeding of The First International Conference on Health Care and Management. 2018. Retrieved from: http://stikepppnijabar.ac.id/conference/index.php/ichm/ichm20 18/paper/view/14/10

19. Jacobsen PB. Assessment of fatigue in cancer patients. Journal of The National Cancer Institute Monographs. 2004.

10.1093/jncimonographs/Igh010.

20. Courneya KS, Rogers LQ, Campbell KL, Vallance JK, Friedenreich CM. Top 10 research questions related to physical activity and cancer survivorship. Research Quarterly for Exercise and Sport. 2015; 86: 107-116.

21. Hulett JM, Armer JM, Stewart BR, Wanchai A. Perspectives of the breast cancer survivorship continuum: diagnosis through 30 months posttreatment. J Pers Med. 2015; 5(2): 174-190.

22. Coughlin SS, Yoo W, Whitehead MS, Smith SA. Advancing breast cancer survivorship among African-American women. Breast Cancer Res Treat. 2015; 153: 253-261.

23. Howell D, Keller-Olaman S, Oliver TK, Hack TF, Broadfield L, Biggs K, Chung J, Gravelle D, Green E, Hamel M, Harth T, Johnston P, McLeod D, Swinton $\mathrm{N}$, Syme A, Olson K. A pan-Canadian practice guideline and algorithm: screening, assessment, and supportive care of adults with cancer-related fatigue. Curr Oncol. 2013; 20(3): e233-46.

24. Anglehart ML. Moving out of the shadow of cancer while living with cancer-related fatigue: identifying the perspective of breast cancer survivors. Thesis. 2006. Wellington, Canada: The University of New Brunswick.

25. Trijayanti E, Probosari E. Correlation between food intake and nutritional status in post-chemotherapy cervical cancer patients (in Bahasa Indonesia). Jurnal Kedokteran Diponegoro. 2016; 5(4): 751-760. 
26. Poort $H$, Kaal SEJ, Knoop $H$, Jansen $R$, Prins JB, Manten-Horst E, Servaes $P$, Husson $O$, van der Graaf WTA. Prevalence and impact of severe fatigue in adolescent and young adult cancer patients in comparison with population-based controls. Support Care Cancer. 2017; 25: 2911-2918.

27. Sari NPWP. Women living with breast and cervical cancer in the community: the face of Surabaya nowadays. Indonesian Journal of Cancer. 2018; 12(4): 116-122.
28. Sari NPWP. Physical wellbeing in cervical and breast cancer survivors: a cross-sectional study in Surabaya, Indonesia. Indonesian Journal of Cancer. 2018; 12(3): 80-87.

29. Sari NPWP. Chemotherapy-Induced Cancer-Related Fatigue in Cervical and Breast Cancer Survivors. Proceedings of Researchfora International Conference. 2018. India: IRAJ Research Forum, Institute of Research and Journals. 